\title{
Hepatocellular carcinoma is the most common liver-related complication in patients with histopathologically-confirmed NAFLD in Japan
}

Norio Akuta ${ }^{1 *}$, Yusuke Kawamura$^{1}$, Yasuji Arase ${ }^{1}$, Satoshi Saitoh ${ }^{1}$, Shunichiro Fujiyama ${ }^{1,1}$, Hitomi Sezaki ${ }^{1}$, Tetsuya Hosaka', Masahiro Kobayashi ${ }^{1}$, Mariko Kobayashi ${ }^{2}$, Yoshiyuki Suzuki ${ }^{1}$, Fumitaka Suzuki ${ }^{1}$, Kenji Ikeda ${ }^{1}$ and Hiromitsu Kumada'

\begin{abstract}
Background: The incidence of liver-related events, cardiovascular events and type 2 diabetes mellitus in patients with histopathologically confirmed NAFLD remains unclear.

Methods: We retrospectively investigated the incidence of liver events, cardiovascular events, malignancy, and type 2 diabetes mellitus in 402 Japanese patients with histopathologically confirmed NAFLD for a median follow-up of 4. 2 years. We also investigated predictors of the development of hepatocellular carcinoma and type 2 diabetes mellitus in these patients.

Results: The rate of liver-related events per 1000 person years was 4.17 (hepatocellular carcinoma, 3.67; hepatic encephalopathy, 1.60; esophago-gastric varices, 2.43; ascites, 0.80; and jaundice, 0.40). The rate of cardiovascular events and type 2 diabetes mellitus was 5.73 and 9.95, respectively. Overall mortality was 3.33 (liver-related events, 1.25; cardiovascular events, 0.42; and malignancies other than hepatocellular carcinoma, 0.83), in patients free of previous or current malignancies. Multivariate analyses identified old age ( $\geq 70$ years) and advanced fibrosis stage 4 as significant determinants of hepatocellular carcinoma development, and hepatocyte steatosis (> 33\%), female sex, and serum ferritin $(\leq 80 \mu \mathrm{g} / \mathrm{l})$ as significant determinants of type 2 diabetes mellitus development in these patients.

Conclusions: Our results highlighted the importance of cardiovascular and liver-related events in Japanese patients with histopathologically-confirmed NAFLD. Hepatocellular carcinoma was the most common liver-related event, and the incidence of hepatocellular carcinoma was more than half of that of cardiovascular events.
\end{abstract}

Keywords: Nonalcoholic fatty liver disease, Nonalcoholic steatohepatitis, Hepatocellular carcinoma, Liver-related events, Cardiovascular events, Type 2 diabetes mellitus, Malignancy, Mortality, Fibrosis stage, Hepatocyte steatosis

\section{Background}

The most common liver disease worldwide is nonalcoholic fatty liver disease (NAFLD) [1-6]. Liver pathology ranges from the typically benign non-alcoholic fatty liver to non-alcoholic steatohepatitis (NASH), which may

\footnotetext{
*Correspondence: akuta-gi@umin.ac.jp; norioakuta@toranomon.gr.jp ${ }^{1}$ Department of Hepatology, Toranomon Hospital and Okinaka Memorial Institute for Medical Research, 2-2-2 Toranomon, Minato-ku, Tokyo 105-0001, Japan

Full list of author information is available at the end of the article
}

progress to liver cirrhosis, hepatocellular carcinoma (HCC), and liver failure [7].

The incidence of liver events, cardiovascular events, malignancy, and type 2 diabetes mellitus (T2DM) in patients with histopathologically confirmed NAFLD remains unclear. T2DM and fibrosis stage are significant and independent risk factors for HCC in patients with NAFLD [5]. Results of recent prospective studies have shown that antidiabetic drugs may improve histological features, including fibrosis stage [8-10]. Thus, it may be important to identify predictors of the development of

(C) The Author(s). 2018 Open Access This article is distributed under the terms of the Creative Commons Attribution 4.0 International License (http://creativecommons.org/licenses/by/4.0/), which permits unrestricted use, distribution, and 
HCC and T2DM to improve the prognosis of patients with NAFLD.

It has been suggested that fibrosis stage may be more reliable than the NAFLD activity score (NAS) for the prediction of liver-specific mortality [11]. Fibrosis stage, but not other histopathological features of steatohepatitis, was reported to be an independent and significant predictor of overall mortality, liver transplantation, and liver-related events [12].

The purpose of the present study was to determine the incidence of liver-related events, cardiovascular events, and $\mathrm{T} 2 \mathrm{DM}$, and the predictors of development of HCC and T2DM in patients with NAFLD by retrospectively analyzing the outcome of 402 Japanese patients with histopathologically confirmed NAFLD.

\section{Methods}

\section{Patients}

This is a retrospective cohort study of patients with histopathologically-confirmed NAFLD. Between 1976 and 2017, liver biopsy was performed at our hospital for patients with liver dysfunction and/or fatty liver diagnosed by abdominal ultrasonography. Of those, the diagnosis of NAFLD was confirmed in 402 patients by histopathology. The median duration of follow-up, from diagnosis to death or last visit, was 4.2 years (range, 0.0 41.4 years), and the total sum of person-years was 2625 years. The characteristics of the patients at the time of histopathological diagnosis of NAFLD are summarized in Table 1. Patients with histopathological changes of steatosis in at least $5 \%$ of hepatocytes and alcohol intake $<20 \mathrm{~g} /$ day were included in the analysis. We excluded patients with 1) underlying liver disease (e.g., viral hepatitis, autoimmune hepatitis, drug-induced liver disease, or primary biliary cirrhosis); 2) systemic autoimmune diseases (e.g., systemic lupus erythematosus and rheumatoid arthritis); and 3) metabolic diseases (e.g., hemochromatosis, $\alpha-1$-antitrypsin deficiency, or Wilson disease).

The study was conducted in compliance with the International Conference on Harmonisation guidelines for Good Clinical Practice (E6) and the 2013 Declaration of Helsinki. The protocol was approved by the institutional review board at Toranomon Hospital number 953). Written informed consent was provided by all patients prior to liver biopsy.

\section{Diagnosis and follow-up}

Liver-related events included HCC, hepatic encephalopathy, esophago-gastric varices with bleeding, ascites, and jaundice. Cardiovascular events included coronary artery disease, heart valve disease, arrhythmia, heart failure, hypertension, orthostatic hypotension, shock, endocarditis, diseases of the aorta and its branches, disorders of
Table 1 Patient characteristics at the time of histological diagnosis of NAFLD

\begin{tabular}{|c|c|}
\hline \multicolumn{2}{|l|}{ Demographic data } \\
\hline Numbers of patients & 402 \\
\hline Gender, Male / Female, n & $245 / 157$ \\
\hline Age, $y^{a}$ & $51(20-87)$ \\
\hline Body mass index, $\mathrm{kg} / \mathrm{m}^{2 a}$ & $26.1(18.1-42.4)$ \\
\hline \multicolumn{2}{|l|}{ Presence of previous and current malignancy } \\
\hline $\begin{array}{l}\text { None / Hepatocellular carcinoma / Other } \\
\text { malignancy, n }\end{array}$ & $351 / 26 / 30$ \\
\hline Type 2 diabetes mellitus, Absence / Presence, $\mathrm{n}$ & $276 / 126$ \\
\hline Hypertension, Absence / Presence, $\mathrm{n}$ & $230 / 172$ \\
\hline Hyperlipidemia, Absence / Presence, n & $274 / 128$ \\
\hline \multicolumn{2}{|l|}{ Histological findings } \\
\hline Steatosis, 5-33\% / > 33-66\% / > 66\%, n & $152 / 149 / 98$ \\
\hline \multicolumn{2}{|l|}{ Lobular inflammation } \\
\hline $\begin{array}{l}\text { No foci / < } 2 \text { foci / } 2-4 \text { foci / > } 4 \text { foci per } 200 \times \\
\text { field, } n\end{array}$ & $\begin{array}{l}28 / 242 / 116 / \\
13\end{array}$ \\
\hline Ballooning, None / Few cells / Many cells, n & $39 / 252 / 108$ \\
\hline Stage, $0 / 1 / 2 / 3 / 4, n$ & $\begin{array}{l}48 / 165 / 63 / 98 \\
/ 28\end{array}$ \\
\hline NAFLD activity score, $\leq 2 / 3,4 / \geq 5, n$ & $34 / 181 / 184$ \\
\hline $\begin{array}{l}\text { Diagnosis according to FLIP algorithm, NASH / } \\
\text { non-NASH, } n\end{array}$ & $349 / 50$ \\
\hline \multicolumn{2}{|l|}{ Laboratory data ${ }^{a}$} \\
\hline Serum aspartate aminotransferase, IU/I & $44(3-378)$ \\
\hline Serum alanine aminotransferase, IU/I & $69(15-783)$ \\
\hline Gamma-glutamyl transpeptidase, IU/I & $72(11-990)$ \\
\hline Platelet count, $\times 10^{3} / \mathrm{mm}^{3}$ & $213(40-471)$ \\
\hline Fasting plasma glucose, mg/dl & $101(65-287)$ \\
\hline $\mathrm{HbA} 1 \mathrm{c}, \%$ & $5.9(4.4-12.6)$ \\
\hline Uric acid, mg/dl & $5.9(1.9-11.1)$ \\
\hline Total cholesterol, mg/dl & $204(101-370)$ \\
\hline Triglycerides, mg/dl & $140(31-1088)$ \\
\hline High-density lipoprotein cholesterol, mg/dl & $45(14-85)$ \\
\hline Low-density lipoprotein cholesterol, mg/dl & $120(27-243)$ \\
\hline Serum ferritin, $\mu \mathrm{g} / \mathrm{l}$ & $227(<10-2067)$ \\
\hline High sensitive C-reactive protein, mg/dl & $\begin{array}{l}0.095(0.006- \\
2.240)\end{array}$ \\
\hline Alpha-fetoprotein, $\mu \mathrm{g} / \mathrm{l}$ & $4(1-10,930)$ \\
\hline PIVKA-II, AU/I & $18(1-157,050)$ \\
\hline
\end{tabular}

Data are number of patients, except those denoted by ${ }^{\mathrm{a}}$, which represent the median (range) values

the peripheral vascular system, and stroke. Furthermore, the incidence of T2DM and other malignancies, apart from HCCs, were also evaluated. The incidence of T2DM was assessed at least twice a year after baseline examination. T2DM was diagnosed as the presence of elevated fasting plasma glucose $(\geq 126 \mathrm{mg} / \mathrm{dl})$, elevated 
HbA1c $(\geq 6.5 \%)$ or self-reported history of clinical diagnosis.

Hematological and biochemical data were collected at least twice yearly after the diagnosis of NAFLD. Ultrasonography, computed tomography, or magnetic resonance imaging studies were performed at least once annually.

The clinical details of the events of 3 patients were missing. The rate of cancer development was evaluated only in patients confirmed to have no previous or existing HCC at the time of diagnosis of NAFLD, and no previous or current other malignancies apart from HCCs. The rates of development of hepatic encephalopathy, esophago-gastric varices, ascites, and jaundice were evaluated in patients confirmed to have no previous or current hepatic encephalopathy, esophago-gastric varices, ascites, jaundice or HCC at the time of NAFLD diagnosis, respectively. Mortality was evaluated in patients, who had no previous or present malignancies at the time of NAFLD diagnosis. Details of patient enrolment are shown in Fig. 1.

\section{Liver histopathology}

Liver specimens were obtained with a 14-gauge modified Vim Silverman needle (Tohoku University style, Kakinuma Factory, Tokyo, Japan), a 16-gauge core tissue biopsy needle (Bard Peripheral Vascular Inc., Tempe, AZ) or surgical resection. Specimen was fixed in $10 \%$ formalin, and the prepared sections were stained with hematoxylin-eosin, Masson trichrome, silver impregnation, or periodic acid-Schiff after diastase digestion. Four pathologists (K.K., F.K., T.F., and T.F.), who were blinded to the clinical findings, evaluated each specimen, and the final assessment was reported by consensus. An

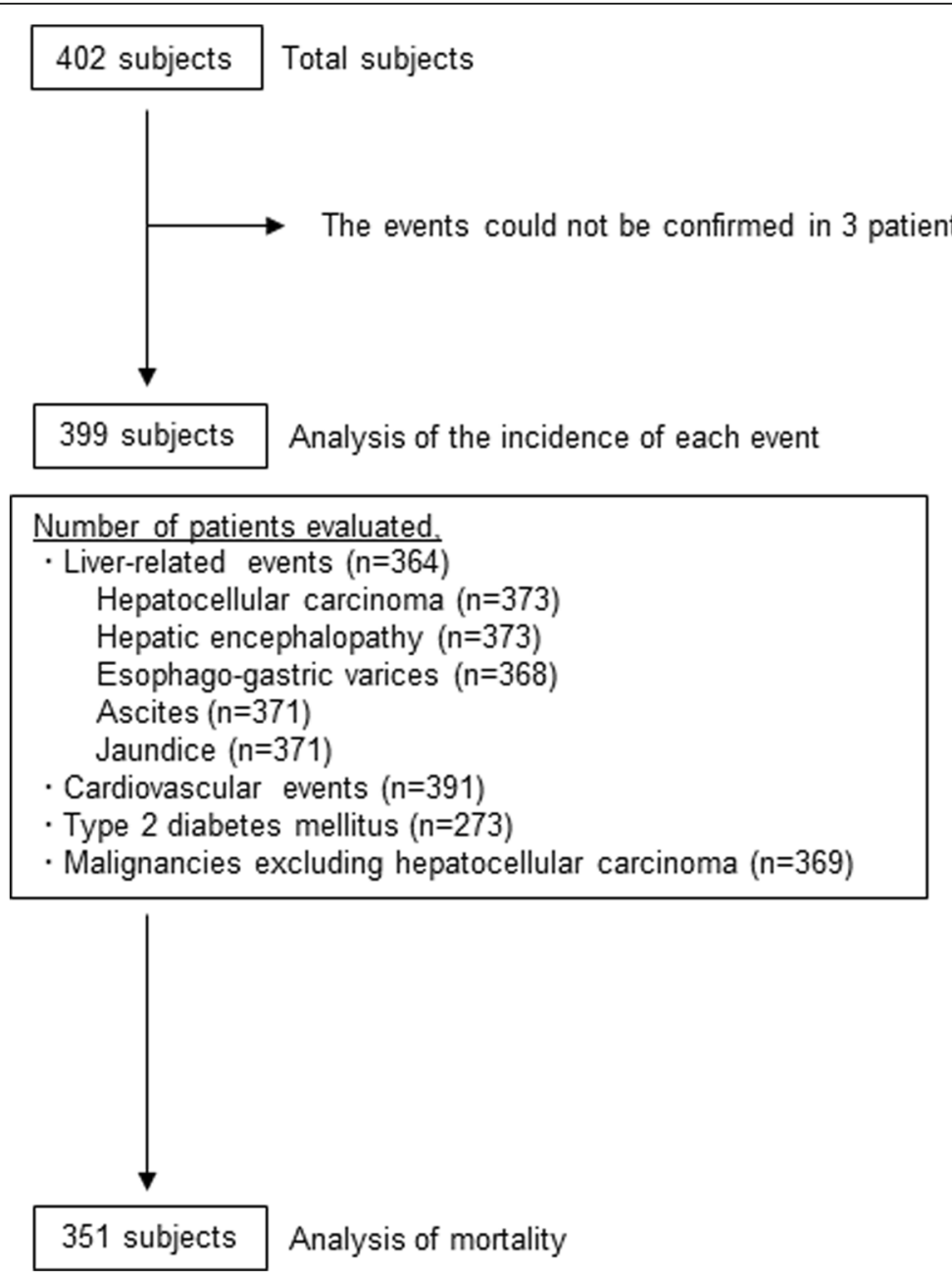

Fig. 1 Between 1976 and 2017, liver biopsy was performed at our hospital, for patients with liver dysfunction and/or fatty liver, as confirmed by abdominal ultrasonography. NAFLD was confirmed histopathologically in 402 Japanese consecutive patients. Follow-up was missing in 3 patients, and 399 patients were evaluated in sub-cohorts in which patients who had experienced an event were excluded from that specific analysis. Mortality was evaluated in 351 patients, without previous or current malignancies at the time of NAFLD diagnosis 
adequate liver biopsy sample was defined as a specimen longer than $1.5 \mathrm{~cm}$ and/or containing more than 11 portal tracts.

Steatosis grade $0,1,2$, and 3 corresponded to steatosis of $<5 \%, \geq 5$ to $<33 \%, \geq 33$ to $<66 \%$, and $\geq 66 \%$ of hepatocytes, respectively. Lobular inflammation with no foci, < 2 foci, $2-4$ foci, and $\geq 4$ foci per $200 \times$ field was scored as $0,1,2$, and 3 , respectively. Hepatocyte ballooning of none, few, and many cells was scored as 0,1 , and 2, respectively. The sum of the steatosis, lobular inflammation, and hepatocyte ballooning scores (range, 0-8 points) was the NAS [13]. Fibrosis stage was defined as $0,1,2,3$, and $4[13,14]$. NASH was defined according to the Fatty Liver Inhibition of Progression (FLIP) algorithm [15].

\section{Clinical parameters}

We analyzed clinicopathological parameters that could affect NAFLD prognosis. At our hospital, the normal range of aspartate aminotransferase (AST) was 13-33 IU/ 1 , and the normal range of alanine aminotransferase (ALT) was 8-42 IU/l for males and 6-27 IU/l for females. Obesity was defined as body mass index of $>25.0 \mathrm{~kg} / \mathrm{m}^{2}$.

\section{Statistical analysis}

The incidence of each event was analyzed during the period from the time of histopathological diagnosis of NAFLD until the last visit or occurrence of event. Stepwise Cox regression analysis was used to determine independent predictive factors associated with the development of HCC and T2DM. The hazard ratio (HR) and 95\% confidence interval (95\% CI) were also calculated. Variables that were statistically significant on univariate analysis were tested by multivariate analysis to identify significant independent factors. Significance was set at $p$ value $<0.05$ by the two-tailed test. Statistical comparisons were performed with the SPSS software (SPSS Inc., Chicago, IL, USA).

\section{Results}

\section{Incidence of liver-related events in NAFLD}

During the follow-up, 9/373 (2.4\%) patients developed HCC (rate per 1000 person years, 3.67), and 21/369 (5.7\%) patients developed malignancies other than HCC (rate per 1000 person years, 8.93).

4/373 (1.1\%) patients developed hepatic encephalopathy (rate per 1000 person years, 1.60). 6/368 (1.6\%) patients developed esophago-gastric varices (rate per 1000 person years, 2.43). 2/371 (0.5\%) patients developed ascites (rate per 1000 person years, 0.80). 1/371 (0.3\%) patient developed jaundice (rate per 1000 person years, 0.40).

Hence, 10 of 364 patients $(2.8 \%)$ confirmed to have no previous or current liver-related events at NAFLD diagnosis developed liver-related events (rate per 1000 person years, 4.17) (Table 2).

Predictors of development of HCC in patients with NAFLD The characteristics of the 373 patients confirmed to have no previous or current $\mathrm{HCC}$ at the time of NAFLD diagnosis were evaluated for prediction of HCC development. Twenty-seven potential predictive factors of the clinicopathological parameters were analyzed (Table 3). Univariate analysis identified the following five parameters that correlated significantly with HCC development: age, fibrosis stage, platelet count, total cholesterol, and $\alpha$-fetoprotein. These factors were entered into multivariate analysis, which identified two factors that significantly and independently influenced HCC development: advanced age ( $\geq 70$ years; $\mathrm{HR} 9.54,95 \% \mathrm{CI}=1.63-55.9$, $P=0.012$ ) and advanced fibrosis stage (stage 4; HR 7.14, 95\% CI $=1.29-39.5, P=0.024$ ) (Table 3 ).

\section{Rate of development of cardiovascular events in NAFLD}

The characteristics of the 391 patients confirmed to have no previous or current cardiovascular events at NAFLD diagnosis were evaluated for the rate of development of cardiovascular events. During the follow-up, 14 patients (3.6\%) developed cardiovascular events, and the development rate per 1000 person years was 5.73 (Table 2).

\section{Rate and predictors of development of T2DM in NAFLD}

The incidence of type 2 diabetes mellitus was evaluated in patients confirmed to have no previous or current T2DM $(n=273)$ at the time of NAFLD diagnosis. During the follow-up, 19 (7.0\%) patients developed T2DM (rate per 1000 person years, 9.95) (Table 2).

The characteristics of the 273 patients confirmed to have no previous or current T2DM at the time of

Table 2 Incidence of liver events, cardiovascular events and type 2 diabetes mellitus in patients with NAFLD

\begin{tabular}{|c|c|c|}
\hline Events & $\mathrm{n} / \mathrm{N}(\%)^{a}$ & $\begin{array}{l}1000 \text { person } \\
\text { years }\end{array}$ \\
\hline Liver-related events ${ }^{\mathrm{b}}$ & 10/364 (2.8\%) & 4.17 \\
\hline Hepatocellular carcinoma & 9/373 (2.4\%) & 3.67 \\
\hline Hepatic encephalopathy & 4/373 (1.1\%) & 1.60 \\
\hline Esophago-gastric varices & $6 / 368(1.6 \%)$ & 2.43 \\
\hline Ascites & $2 / 371(0.5 \%)$ & 0.80 \\
\hline Jaundice & $1 / 371(0.3 \%)$ & 0.40 \\
\hline Cardiovascular events & 14/391 (3.6\%) & 5.73 \\
\hline Type 2 diabetes mellitus & 19/273 (7.0\%) & 9.95 \\
\hline $\begin{array}{l}\text { Malignancies except for } \\
\text { hepatocellular carcinoma }\end{array}$ & $21 / 369(5.7 \%)$ & 8.93 \\
\hline
\end{tabular}


Table 3 Predictors of development of hepatocellular carcinoma in patients with NAFLD

\begin{tabular}{|c|c|c|c|c|c|c|c|}
\hline \multirow[t]{2}{*}{ Factor } & \multirow[t]{2}{*}{ Category } & Univariate & $(95 \% \mathrm{Cl})$ & \multirow{2}{*}{$\begin{array}{l}P \\
\text { value }^{*}\end{array}$} & Multivariate & \multirow[t]{2}{*}{$(95 \% \mathrm{Cl})$} & \multirow{2}{*}{$\begin{array}{l}P \\
\text { value* }\end{array}$} \\
\hline & & \multicolumn{2}{|l|}{ Hazard ratio } & & Hazard ratio & & \\
\hline \multicolumn{8}{|l|}{ Demographic data } \\
\hline \multirow[t]{2}{*}{ Gender } & Male & 1 & & & & & \\
\hline & Female & 0.24 & $(0.03-1.97)$ & 0.186 & & & \\
\hline \multirow[t]{2}{*}{ Age } & $<70 y$ & 1 & & & 1 & & \\
\hline & $\geq 70 y$ & 18.6 & $(3.74-92.6)$ & $<0.001$ & 9.54 & $(1.63-55.9)$ & 0.012 \\
\hline \multirow[t]{2}{*}{ Body mass index } & $<25.0 \mathrm{~kg} / \mathrm{m}^{2}$ & 1 & & & & & \\
\hline & $\geq 25.0 \mathrm{~kg} / \mathrm{m}^{2}$ & 0.46 & $(0.11-1.88)$ & 0.276 & & & \\
\hline \multirow[t]{2}{*}{ Type 2 diabetes mellitus } & Absence & 1 & & & & & \\
\hline & Presence & 3.64 & $(0.95-14.0)$ & 0.060 & & & \\
\hline \multirow[t]{2}{*}{ Hypertension } & Absence & 1 & & & & & \\
\hline & Presence & 1.06 & $(0.28-3.95)$ & 0.932 & & & \\
\hline \multirow[t]{2}{*}{ Hyperlipidemia } & Absence & 1 & & & & & \\
\hline & Presence & 0.36 & $(0.05-2.91)$ & 0.339 & & & \\
\hline \multicolumn{8}{|l|}{ Histological findings } \\
\hline \multirow[t]{2}{*}{ Steatosis } & $5-33 \%$ & 1 & & & & & \\
\hline & $>33 \%$ & 0.40 & $(0.10-1.63)$ & 0.201 & & & \\
\hline \multirow[t]{2}{*}{ Lobular inflammation } & $<2$ foci per $200 \times$ field & 1 & & & & & \\
\hline & $\geq 2$ foci per $200 \times$ field & 0.31 & $(0.04-2.50)$ & 0.272 & & & \\
\hline \multirow[t]{2}{*}{ Ballooning } & None / Few cells & 1 & & & & & \\
\hline & Many cells & 0.47 & $(0.05-3.84)$ & 0.482 & & & \\
\hline \multirow[t]{2}{*}{ Stage } & $0-3$ & 1 & & & 1 & & \\
\hline & 4 & 33.9 & $(7.14-161)$ & $<0.001$ & 7.14 & $(1.29-39.5)$ & 0.024 \\
\hline \multirow[t]{2}{*}{ NAFLD activity score } & $<5$ & 1 & & & & & \\
\hline & $\geq 5$ & 0.19 & $(0.02-1.50)$ & 0.114 & & & \\
\hline \multirow[t]{2}{*}{ Diagnosis according to FLIP algorithm } & non-NASH & 1 & & & & & \\
\hline & $\mathrm{NASH}$ & 1.34 & $(0.17-10.8)$ & 0.784 & & & \\
\hline \multicolumn{8}{|l|}{ Laboratory data } \\
\hline \multirow[t]{2}{*}{ Serum aspartate aminotransferase } & $<2 \times$ ULN IU/I & 1 & & & & & \\
\hline & $\geq 2 \times U L N$ IU/I & 2.74 & $(0.73-10.2)$ & 0.134 & & & \\
\hline \multirow[t]{2}{*}{ Serum alanine aminotransferase } & $<2 \times$ ULN IU/I & 1 & & & & & \\
\hline & $\geq 2 \times U L N$ IU/I & 0.85 & $(0.22-3.22)$ & 0.810 & & & \\
\hline Gamma-glutamyl transpeptidase & $<110 \mathrm{IU} / \mathrm{I}$ & 1 & & & & & \\
\hline & $\geq 110 \mathrm{IU} / \mathrm{I}$ & 1.29 & $(0.34-4.86)$ & 0.706 & & & \\
\hline Platelet count & $<200 \times 10^{3} / \mathrm{mm}^{3}$ & 1 & & & 1 & & \\
\hline & $\geq 200 \times 10^{3} / \mathrm{mm}^{3}$ & 0.06 & $(0.01-0.50)$ & 0.009 & 0.14 & $(0.01-1.33)$ & 0.086 \\
\hline Fasting plasma glucose & $<110 \mathrm{mg} / \mathrm{dl}$ & 1 & & & & & \\
\hline & $\geq 110 \mathrm{mg} / \mathrm{dl}$ & 3.61 & $(0.85-15.3)$ & 0.081 & & & \\
\hline $\mathrm{HbA1c}$ & $<5.8 \%$ & 1 & & & & & \\
\hline & $\geq 5.8 \%$ & 56.2 & $(0.01-634,349)$ & 0.397 & & & \\
\hline Uric acid & $<7.1 \mathrm{mg} / \mathrm{dl}$ & 1 & & & & & \\
\hline & $\geq 7.1 \mathrm{mg} / \mathrm{dl}$ & 0.03 & $(0.00-21.0)$ & 0.298 & & & \\
\hline Total cholesterol & $<200 \mathrm{mg} / \mathrm{dl}$ & 1 & & & & & \\
\hline & $\geq 200 \mathrm{mg} / \mathrm{dl}$ & 0.18 & $(0.04-0.87)$ & 0.033 & & & \\
\hline
\end{tabular}


Table 3 Predictors of development of hepatocellular carcinoma in patients with NAFLD (Continued)

\begin{tabular}{|c|c|c|c|c|c|c|c|}
\hline \multirow[t]{2}{*}{ Factor } & \multirow[t]{2}{*}{ Category } & Univariate & $(95 \% \mathrm{Cl})$ & \multirow{2}{*}{$\begin{array}{l}P \\
\text { value* }\end{array}$} & Multivariate & \multirow[t]{2}{*}{$(95 \% \mathrm{Cl})$} & \multirow{2}{*}{$\begin{array}{l}P \\
\text { value* }\end{array}$} \\
\hline & & \multicolumn{2}{|l|}{ Hazard ratio } & & Hazard ratio & & \\
\hline \multirow[t]{2}{*}{ Triglycerides } & $<150 \mathrm{mg} / \mathrm{dl}$ & 1 & & & & & \\
\hline & $\geq 150 \mathrm{mg} / \mathrm{dl}$ & 0.46 & $(0.09-2.28)$ & 0.342 & & & \\
\hline \multirow[t]{2}{*}{ High-density lipoprotein cholesterol } & $<41 \mathrm{mg} / \mathrm{dl}$ & 1 & & & & & \\
\hline & $\geq 41 \mathrm{mg} / \mathrm{dl}$ & 0.58 & $(0.15-2.25)$ & 0.428 & & & \\
\hline \multirow[t]{2}{*}{ Low-density lipoprotein cholesterol } & $<136 \mathrm{mg} / \mathrm{dl}$ & 1 & & & & & \\
\hline & $\geq 136 \mathrm{mg} / \mathrm{dl}$ & 0.24 & $(0.03-2.06)$ & 0.191 & & & \\
\hline \multirow[t]{2}{*}{ Serum ferritin } & $<81 \mu \mathrm{g} / \mathrm{l}$ & 1 & & & & & \\
\hline & $\geq 81 \mu \mathrm{g} / \mathrm{l}$ & 0.71 & $(0.14-3.61)$ & 0.674 & & & \\
\hline \multirow[t]{2}{*}{ High sensitive C-reactive protein } & $<0.2 \mathrm{mg} / \mathrm{dl}$ & 1 & & & & & \\
\hline & $\geq 0.2 \mathrm{mg} / \mathrm{dl}$ & 1.02 & $(0.11-10.0)$ & 0.984 & & & \\
\hline \multirow[t]{2}{*}{ Alpha-fetoprotein } & $<5 \mu g / l$ & 1 & & & 1 & & \\
\hline & $\geq 5 \mu \mathrm{g} / \mathrm{l}$ & 7.15 & $(1.44-35.6)$ & 0.016 & 4.44 & $(0.84-23.4)$ & 0.079 \\
\hline \multirow[t]{2}{*}{ PIVKA-II } & $<21 \mathrm{AU} / \mathrm{I}$ & 1 & & & & & \\
\hline & $\geq 21 \mathrm{AU} / \mathrm{I}$ & 0.47 & $(0.06-4.05)$ & 0.495 & & & \\
\hline
\end{tabular}

*Significance was determined using a Cox proportional hazard model. Cl confidence interval, ULN upper limit of normal

histopathological diagnosis of NAFLD were evaluated for prediction of T2DM development. Twenty-six potential predictive factors of the clinicopathological parameters were analyzed (Table 4). Univariate analysis identified the following five parameters that correlated significantly with T2DM development: gender, hepatocyte steatosis, $\gamma$-glutamyl transpeptidase, low-density lipoprotein cholesterol, and serum ferritin. These factors were entered into multivariate analysis, which identified three factors that significantly and independently influenced T2DM development: gender (female; HR 5.83, 95\% CI $=1.47-$ 23.1, $P=0.012$ ), hepatocyte steatosis (> 33\%; HR 9.52, 95\% $\mathrm{CI}=1.57-57.6, P=0.014)$, and serum ferritin $(\geq 81 \mu \mathrm{g} / \mathrm{l}$; HR 0.18, 95\% CI = 0.06-0.56, $P=0.003$ ) (Table 4).

\section{Mortality in NAFLD, without previous or current malignancies}

In patients without previous or present malignancies at the time of NAFLD diagnosis, the overall mortality per 1000 person years was 3.33. The rate was 1.25 for those who died of liver-related events, 0.42 for those who died of cardiovascular events, and 0.83 for those who died of malignancies events other than HCC (Table 5). In the 3 patients who died from liver-related events, 2 of 3 patients and 1 of 3 patients had HCC and liver failure, respectively.

\section{Discussion}

The incidence of liver-related and cardiovascular events in patients with histopathologically confirmed NAFLD remains unclear. Furthermore, it is important to identify the predictors of development of HCC and T2DM to improve the prognosis of patients with NAFLD. There is limited information on the long-term development rate of these events in patients with histopathologically confirmed NAFLD [16, 17].

We found that patients with NAFLD were at increased risk of $\mathrm{HCC}(\mathrm{HR} 6.55, P=0.001)$ and cardiovascular diseases (HR 1.55, $P=0.01$ ) [18]. In the present study, cardiovascular events had the highest incidence (5.73 per 1000 person years), with liver-related events the second highest incidence (4.17 per 1000 person years). Interestingly, among liver-related events, HCC was the event with the highest incidence (3.67 per 1000 person years). The incidence of HCC was more than half of that of cardiovascular events (3.67 vs. 5.73 per 1000 person years). In the present study, the mortality of liver-related events per 1000 person years (1.25) was not lower than that of cardiovascular events (0.42) and malignancies other than HCC (0.83). Hence, liver-related events accounted for about one-third of mortality in NAFLD patients who presented with no previous or present malignancies at the time of NAFLD diagnosis.

The present study has certain limitations. First, only a small number of deaths (8 patients) were recorded during the study period. Further studies of larger number of patients with NAFLD and longer follow-up period should be performed to investigate the impact of each event on mortality.

In another study, the incidence of HCC among all malignancies reported in 1600 patients with NAFLD diagnosed based on the presence of fatty liver by ultrasonography, was $6.0 \%$, and the rate per 1000 person 
Table 4 Predictors of development of type 2 diabetes mellitus in patients with NAFLD

\begin{tabular}{|c|c|c|c|c|c|c|c|}
\hline \multirow[t]{2}{*}{ Factor } & \multirow[t]{2}{*}{ Category } & Univariate & $(95 \% \mathrm{Cl})$ & \multirow{2}{*}{$\begin{array}{l}P \\
\text { value* }\end{array}$} & Multivariate & \multirow[t]{2}{*}{$(95 \% \mathrm{Cl})$} & \multirow{2}{*}{$\begin{array}{l}P \\
\text { value* }\end{array}$} \\
\hline & & \multicolumn{2}{|l|}{ Hazard ratio } & & Hazard ratio & & \\
\hline \multicolumn{8}{|l|}{ Demographic data } \\
\hline \multirow[t]{2}{*}{ Gender } & Male & 1 & & & 1 & & \\
\hline & Female & 5.59 & $(2.07-15.1)$ & 0.001 & 5.83 & $(1.47-23.1)$ & 0.012 \\
\hline \multirow[t]{2}{*}{ Age } & $<70 y$ & 1 & & & & & \\
\hline & $\geq 70 y$ & 0.05 & $(0.00-5618)$ & 0.606 & & & \\
\hline \multirow[t]{2}{*}{ Body mass index } & $<25.0 \mathrm{~kg} / \mathrm{m}^{2}$ & 1 & & & & & \\
\hline & $\geq 25.0 \mathrm{~kg} / \mathrm{m}^{2}$ & 1.41 & $(0.56-3.57)$ & 0.472 & & & \\
\hline \multirow[t]{2}{*}{ Hypertension } & Absence & 1 & & & & & \\
\hline & Presence & 1.53 & $(0.62-3.77)$ & 0.357 & & & \\
\hline \multirow[t]{2}{*}{ Hyperlipidemia } & Absence & 1 & & & & & \\
\hline & Presence & 1.20 & $(0.43-3.56)$ & 0.732 & & & \\
\hline \multicolumn{8}{|l|}{ Histological findings } \\
\hline \multirow[t]{2}{*}{ Steatosis } & $5-33 \%$ & 1 & & & 1 & & \\
\hline & $>33 \%$ & 3.30 & $(1.09-10.0)$ & 0.035 & 9.52 & $(1.57-57.6)$ & 0.014 \\
\hline \multirow[t]{2}{*}{ Lobular inflammation } & $<2$ foci per $200 \times$ field & 1 & & & & & \\
\hline & $\geq 2$ foci per $200 \times$ field & 1.70 & $(0.63-4.57)$ & 0.296 & & & \\
\hline \multirow[t]{2}{*}{ Ballooning } & None / Few cells & 1 & & & & & \\
\hline & Many cells & 0.57 & $(0.13-2.49)$ & 0.452 & & & \\
\hline \multirow[t]{2}{*}{ Stage } & $0-3$ & 1 & & & & & \\
\hline & 4 & 1.47 & $(0.20-11.0)$ & 0.711 & & & \\
\hline \multirow[t]{2}{*}{ NAFLD activity score } & $<5$ & 1 & & & & & \\
\hline & $\geq 5$ & 1.30 & $(0.51-3.26)$ & 0.583 & & & \\
\hline \multirow[t]{2}{*}{ Diagnosis according to FLIP algorithm } & non-NASH & 1 & & & & & \\
\hline & $\mathrm{NASH}$ & 1.42 & $(0.41-4.90)$ & 0.579 & & & \\
\hline \multicolumn{8}{|l|}{ Laboratory data } \\
\hline \multirow[t]{2}{*}{ Serum aspartate aminotransferase } & $<2 \times$ ULN IU/I & 1 & & & & & \\
\hline & $\geq 2 \times$ ULN IU/I & 1.19 & $(0.45-3.13)$ & 0.730 & & & \\
\hline \multirow[t]{2}{*}{ Serum alanine aminotransferase } & $<2 \times$ ULN IU/I & 1 & & & & & \\
\hline & $\geq 2 \times$ ULN IU/I & 1.47 & $(0.59-3.64)$ & 0.408 & & & \\
\hline Gamma-glutamyl transpeptidase & $<110 \mathrm{IU} / \mathrm{I}$ & 1 & & & & & \\
\hline & $\geq 110 \mathrm{IU} / \mathrm{I}$ & 0.28 & $(0.08-0.96)$ & 0.043 & & & \\
\hline Platelet count & $<200 \times 10^{3} / \mathrm{mm}^{3}$ & 1 & & & & & \\
\hline & $\geq 200 \times 10^{3} / \mathrm{mm}^{3}$ & 1.94 & $(0.64-5.87)$ & 0.239 & & & \\
\hline Fasting plasma glucose & $<110 \mathrm{mg} / \mathrm{dl}$ & 1 & & & & & \\
\hline & $\geq 110 \mathrm{mg} / \mathrm{dl}$ & 1.31 & $(0.37-4.62)$ & 0.672 & & & \\
\hline $\mathrm{HbA1c}$ & $<5.8 \%$ & 1 & & & & & \\
\hline & $\geq 5.8 \%$ & 2.33 & $(0.32-16.9)$ & 0.404 & & & \\
\hline Uric acid & $<7.1 \mathrm{mg} / \mathrm{dl}$ & 1 & & & & & \\
\hline & $\geq 7.1 \mathrm{mg} / \mathrm{dl}$ & 1.28 & $(0.49-3.38)$ & 0.615 & & & \\
\hline Total cholesterol & $<200 \mathrm{mg} / \mathrm{dl}$ & 1 & & & & & \\
\hline & $\geq 200 \mathrm{mg} / \mathrm{dl}$ & 2.43 & $(0.80-7.34)$ & 0.116 & & & \\
\hline Triglycerides & $<150 \mathrm{mg} / \mathrm{dl}$ & 1 & & & & & \\
\hline & $\geq 150 \mathrm{mg} / \mathrm{dl}$ & 0.78 & $(0.31-1.97)$ & 0.594 & & & \\
\hline
\end{tabular}


Table 4 Predictors of development of type 2 diabetes mellitus in patients with NAFLD (Continued)

\begin{tabular}{|c|c|c|c|c|c|c|c|}
\hline \multirow[t]{2}{*}{ Factor } & \multirow[t]{2}{*}{ Category } & Univariate & $(95 \% \mathrm{Cl})$ & \multirow{2}{*}{$\begin{array}{l}P \\
\text { value* }\end{array}$} & Multivariate & \multirow[t]{2}{*}{$(95 \% \mathrm{Cl})$} & \multirow{2}{*}{$\begin{array}{l}P \\
\text { value* }\end{array}$} \\
\hline & & \multicolumn{2}{|l|}{ Hazard ratio } & & Hazard ratio & & \\
\hline \multirow[t]{2}{*}{ High-density lipoprotein cholesterol } & $<41 \mathrm{mg} / \mathrm{dl}$ & 1 & & & & & \\
\hline & $\geq 41 \mathrm{mg} / \mathrm{dl}$ & 0.49 & $(0.20-1.20)$ & 0.117 & & & \\
\hline \multirow[t]{2}{*}{ Low-density lipoprotein cholesterol } & $<136 \mathrm{mg} / \mathrm{dl}$ & 1 & & & & & \\
\hline & $\geq 136 \mathrm{mg} / \mathrm{dl}$ & 3.20 & $(1.06-9.69)$ & 0.040 & & & \\
\hline \multirow[t]{2}{*}{ Serum ferritin } & $<81 \mu \mathrm{g} / \mathrm{l}$ & 1 & & & 1 & & \\
\hline & $\geq 81 \mu \mathrm{g} / \mathrm{l}$ & 0.26 & $(0.10-0.70)$ & 0.008 & 0.18 & $(0.06-0.56)$ & 0.003 \\
\hline \multirow[t]{2}{*}{ High sensitive C-reactive protein } & $<0.2 \mathrm{mg} / \mathrm{dl}$ & 1 & & & & & \\
\hline & $\geq 0.2 \mathrm{mg} / \mathrm{dl}$ & 1.84 & $(0.57-5.97)$ & 0.312 & & & \\
\hline \multirow[t]{2}{*}{ Alpha-fetoprotein } & $<5 \mu \mathrm{g} / \mathrm{l}$ & 1 & & & & & \\
\hline & $\geq 5 \mu \mathrm{g} / \mathrm{l}$ & 1.08 & $(0.38-3.04)$ & 0.887 & & & \\
\hline \multirow[t]{2}{*}{ PIVKA-II } & $<21 \mathrm{AU} / \mathrm{I}$ & 1 & & & & & \\
\hline & $\geq 21 \mathrm{AU} / \mathrm{I}$ & 0.23 & $(0.03-1.79)$ & 0.160 & & & \\
\hline
\end{tabular}

*Significance was determined using a Cox proportional hazard model. Cl confidence interval, ULN upper limit of normal

years was $0.78,[19]$. However, the results of our study indicated that the rate per 1000 person years was 3.67, and rate of HCC was higher compared to the above studies. The discrepant results could reflect patient selection bias, as all patients had histopathologically confirmed NAFLD, with elevated aminotransferases (indicators of high activity) and/or low levels of platelet counts (indicator of advanced fibrosis stage). Furthermore, patients treated with anti-platelet agents and anticoagulants for the prevention of cardiovascular events, did not undergo liver biopsy, and were thus not included. Also, patients who visit the hospital regularly tend to receive treatments for hypertension, hyperlipidemia, and diabetes mellitus, which are as risk factors of cardiovascular events. As previously reported [5], multivariate analysis identified advanced fibrosis stage and old age as significant and independent determinants of $\mathrm{HCC}$ development.

Seko and colleagues [20] reported that 13 of 89 (14.6\%) patients with biopsy-confirmed NAFLD developed T2DM, and multivariate analysis identified the presence of insulin resistance as an independent risk

Table 5 Mortality in patients with NAFLD, without previous and current malignancies

\begin{tabular}{lll}
\hline Cause of death & $\mathrm{n} / \mathrm{N}(\%)^{\mathrm{a}}$ & $\begin{array}{l}1000 \text { person } \\
\text { years }\end{array}$ \\
\hline Overall & $8 / 351(2.3 \%)$ & 3.33 \\
Liver-related events & $3 / 351(0.9 \%)$ & 1.25 \\
Cardiovascular events & $1 / 351(0.3 \%)$ & 0.42 \\
$\begin{array}{l}\text { Malignancies events except } \\
\text { for hepatocellular carcinoma }\end{array}$ & $2 / 351(0.6 \%)$ & 0.83 \\
Other events & 2/351 (0.6\%) & 0.83 \\
\hline
\end{tabular}

${ }^{a} \mathrm{n}$; number of events. $\mathrm{N}$; number of patients, not having, or having had, the respective event simultaneously or previously to the time of NAFLD diagnosis factor for the development of T2DM. The present study showed that 19 of 273 (6.96\%) patients developed T2DM, which is a lower rate compared to the above study. The discrepant results could be due to differences in the diagnostic methods for T2DM; patients in the previous study were diagnosed with a 75 -g oral glucose tolerance test. The other reasons for the low frequency of T2DM development is probably that many patients had diabetes at the time of liver biopsy and the follow-up time was short, i.e. selection bias and short follow-up. Interestingly, multivariate analysis in the present study identified higher frequencies of hepatocyte steatosis, lower levels of serum ferritin, and female sex as significant and independent determinants of the incidence of T2DM. Previous reports showed that the incidence of T2DM is higher in postmenopausal female patients with hepatocyte steatosis $[17,21]$. However, at this stage, we do not known why lower levels of serum ferritin influence the incidence of T2DM. This finding must be further explored and validated in a larger independent cohort.

Other limitations of the present study included the retrospective study design and the fact that the patients in our study were inpatients. We could not investigate whether factors during the course of observation, such as weight loss and exercise, might affect the development of HCC and T2DM. Furthermore, all participants were Japanese, and thus the results might not be applicable to patients of other races or ethnic groups. Also, the study did not address the epidemiological burden and complexity of the natural history of NAFLD [22, 23]. Identification of predictors of development of $\mathrm{HCC}$ and T2DM in patients with NAFLD is a clinical priority due to the currently available suboptimal surveillance criteria $[5,24]$. 
In conclusion, the results of the present study suggest that cardiovascular and liver-related events are important in Japanese patients with histopathologically-confirmed NAFLD. Especially, HCC was the most common liver-related event, and the incidence of $\mathrm{HCC}$ was more than half of that of cardiovascular events. It may be important to identify fibrosis stage and hepatocyte steatosis as determinants of HCC and T2DM, respectively. Further large-scale prospective studies should be performed to identify the predictors of development of HCC and T2DM to improve the prognosis of patients with NAFLD.

\section{Conclusions}

Hepatocellular carcinoma was the most common liver-related event in Japanese patients with histopathologically-confirmed NAFLD.

\section{Abbreviations \\ ALT: alanine aminotransferase; AST: aspartate aminotransferase; Cl: confidence interval; FLIP: Fatty Liver Inhibition of Progression; HbA1c: Glycated hemoglobin type A1c; HCC: hepatocellular carcinoma; HR: hazard ratio; NAFLD: non-alcoholic fatty liver disease; NAS: NAFLD activity score; NASH: non-alcoholic steatohepatitis; T2DM: type 2 diabetes mellitus}

\section{Acknowledgments}

The authors thank Drs. Keiichi Kinowaki and Takeshi Fujii (Department of Pathology, Toranomon Hospital) and also Drs. Fukuo Kondo and Toshio Fukusato (Department of Pathology, Teikyo University School of Medicine) for assistance in histopathological diagnosis.

\section{Disclaimers}

This paper has not been published or presented elsewhere in part or in entirety, and is not under consideration by another journal.

\section{Funding}

This study was supported in part by Grant-in-Aid from Japan Agency for Medical Research and Development (17fk0210304h0003).

\section{Availability of data and materials}

The datasets generated and/or analyzed in the present study are available from the corresponding author on reasonable request.

\section{Authors' contributions}

N.A., Y.K., Y.A., S.S., S.F., H.S., T.H., M.K. (Masahiro Kobayashi), M.K. (Mariko Kobayashi), Y.S., F.S., K.I., and H.K. contributed to this work. N.A., Y.K., and Y.A. analyzed the data. N.A. wrote the manuscript. All authors read and approved the final manuscript.

\section{Ethics approval and consent to participate}

The study was conducted in compliance with the International Conference on Harmonization guidelines for Good Clinical Practice (E6) and the 2013 Declaration of Helsinki. The protocol was approved by the institutional review board at Toranomon Hospital (number; 953). Written informed consent was provided by all patients prior to liver biopsy.

\section{Consent for publication}

Not Applicable.

\section{Competing interests}

(1) Hiromitsu Kumada has received honoraria from MSD K.K., Bristol-Myers Squibb, Gilead Sciences, AbbVie Inc., and Dainippon Sumitomo Pharma. (2) Norio Akuta has received an honorarium from Bristol-Myers Squibb and AbbVie Inc. (3) Yoshiyuki Suzuki has received an honorarium from Bristol-Myers Squibb and AbbVie Inc. All other authors declare no conflict of interest.

\section{Publisher's Note}

Springer Nature remains neutral with regard to jurisdictional claims in published maps and institutional affiliations.

\section{Author details}

${ }^{1}$ Department of Hepatology, Toranomon Hospital and Okinaka Memorial Institute for Medical Research, 2-2-2 Toranomon, Minato-ku, Tokyo 105-0001, Japan. ${ }^{2}$ Liver Research Laboratory, Toranomon Hospital, Tokyo, Japan.

Received: 28 May 2018 Accepted: 25 October 2018

Published online: 06 November 2018

\section{References}

1. Angulo P. Nonalcoholic fatty liver disease. N Engl J Med. 2002;346:1221-31.

2. Williams R. Global changes in liver disease. Hepatology. 2006;44:521-6.

3. Torres DM, Harrison SA. Diagnosis and therapy of nonalcoholic steatohepatitis. Gastroenterology. 2008;134:1682-98.

4. Vuppalanchi R, Chalasani N. Nonalcoholic fatty liver disease and nonalcoholic steatohepatitis: selected practical issues in their evaluation and management. Hepatology. 2009:49:306-17.

5. Kawamura Y, Arase Y, Ikeda K, Seko Y, Imai N, Hosaka T, et al. Large-scale long-term follow-up study of Japanese patients with non-alcoholic fatty liver disease for the onset of hepatocellular carcinoma. Am J Gastroenterol. 2012;107:253-61.

6. Sumida Y, Nakajima A, Itoh Y. Limitations of liver biopsy and non-invasive diagnostic tests for the diagnosis of nonalcoholic fatty liver disease/ nonalcoholic steatohepatitis. World J Gastroenterol. 2014;20:475-85.

7. Kleiner DE, Brunt EM. Nonalcoholic fatty liver disease: pathologic patterns and biopsy evaluation in clinical research. Semin Liver Dis. 2012;32:3-13.

8. Sanyal AJ, Chalasani N, Kowdley KV, McCullough A, Diehl AM, Bass NM, et al. Pioglitazone, vitamin E, or placebo for nonalcoholic steatohepatitis. N Engl J Med. 2010;362:1675-85.

9. Armstrong MJ, Gaunt P, Aithal GP, Barton D, Hull D, Parker R, et al. Liraglutide safety and efficacy in patients with non-alcoholic steatohepatitis (LEAN): a multicentre, double-blind, randomised, placebo-controlled phase 2 study. Lancet. 2016;387:679-90.

10. Akuta N, Watanabe C, Kawamura Y, Arase Y, Saitoh S, Fujiyama S, et al. Effects of a sodium - glucose cotransporter 2 inhibitor in nonalcoholic fatty liver disease complicated by diabetes mellitus: preliminary prospective study based on serial liver biopsies. Hepatol Commun. 2017;1:46-52.

11. Younossi ZM, Stepanova M, Rafiq N, Makhlouf H, Younoszai Z, Agrawal R, et al. Pathologic criteria for nonalcoholic steatohepatitis: Interprotocol agreement and ability to predict liver-related mortality. Hepatology. 2011;53:1874-82.

12. Angulo P, Kleiner DE, Dam-Larsen $S$, Adams LA, Bjornsson ES, Charatcharoenwitthaya $P$, et al. Liver fibrosis, but no other histologic features, is associated with long-term outcomes of patients with nonalcoholic fatty liver disease. Gastroenterology. 2015;149:389-97.

13. Kleiner DE, Brunt EM, Van Natta M, Behling C, Contos MJ, Cummings OW, et al. Design and validation of a histological scoring system for nonalcoholic fatty liver disease. Hepatology. 2005;41:1313-21.

14. Brunt EM, Janney CG, Di Bisceglie AM, Neuschwander-Tetri BA, Bacon BR. Nonalcoholic steatohepatitis: a proposal for grading and staging the histological lesions. Am J Gastroenterol. 1999;94:2467-74.

15. Bedossa P. Utility and appropriateness of the fatty liver inhibition of progression (FLIP) algorithm and steatosis, activity, and fibrosis (SAF) score in the evaluation of biopsies of nonalcoholic fatty liver disease. Hepatology. 2014;60:565-75.

16. Hagström H, Nasr P, Ekstedt M, Hammar U, Stål P, Hultcrantz R, et al. Fibrosis stage but not NASH predicts mortality and time to development of severe liver disease in biopsy-proven NAFLD. J Hepatol. 2017;67:1265-73.

17. Björkström K, Stål P, Hultcrantz R, Hagström H. Histologic scores for fat and fibrosis associate with development of type 2 diabetes in patients with nonalcoholic fatty liver disease. Clin Gastroenterol Hepatol. 2017;15:1461-8.

18. Ekstedt M, Hagström H, Nasr P, Fredrikson M, Stål P, Kechagias S, et al. Fibrosis stage is the strongest predictor for disease-specific mortality in NAFLD after up to 33 years of follow-up. Hepatology. 2015;61:1547-54.

19. Arase $Y$, Kobayashi M, Suzuki F, Suzuki $Y$, Kawamura $Y$, Akuta N, et al. Difference in malignancies of chronic liver disease due to non-alcoholic fatty liver disease or hepatitis $C$ in Japanese elderly patients. Hepatol Res. 2012;42:264-72. 
20. Seko Y, Sumida Y, Tanaka S, Mori K, Taketani H, Ishiba H, et al. Insulin resistance increases the risk of incident type 2 diabetes mellitus in patients with non-alcoholic fatty liver disease. Hepatol Res. 2017 Jun 19. [Epub ahead of print].

21. Gaspard U. Hyperinsulinaemia, a key factor of the metabolic syndrome in postmenopausal women. Maturitas. 2009;62:362-5.

22. Lonardo A, Bellentani S, Argo CK, Ballestri S, Byrne CD, Caldwell SH, et al. Epidemiological modifiers of non-alcoholic fatty liver disease: focus on highrisk groups. Dig Liver Dis. 2015;47:997-1006.

23. Lonardo A, Sookoian S, Chonchol M, Loria P, Targher G. Cardiovascular and systemic risk in nonalcoholic fatty liver disease - atherosclerosis as a major player in the natural course of NAFLD. Curr Pharm Des. 2013;19:5177-92.

24. Della Corte C, Colombo M. Surveillance for hepatocellular carcinoma. Semin Oncol. 2012;39:384-98.

Ready to submit your research? Choose BMC and benefit from:

- fast, convenient online submission

- thorough peer review by experienced researchers in your field

- rapid publication on acceptance

- support for research data, including large and complex data types

- gold Open Access which fosters wider collaboration and increased citations

- maximum visibility for your research: over $100 \mathrm{M}$ website views per year

At $\mathrm{BMC}$, research is always in progress.

Learn more biomedcentral.com/submissions 